$11,1936)$, in which he dwells on continuity in type as a regional characteristic. Analogies to archæological finds, he points out, have been sought among primitive peoples, geographically remote, and often have led to erroneous results; whereas investigation in the area in which they were found, among the people of to-day, would have revealed in many instances the identical type, or a derivative, in everyday use. M. Franchet himself has interpreted his archæological finds by this method with illuminating effect, and he has also traced modern implements back to their origin in the bronze age. His researches in the forest of Montmorency find an ancestry for certain implements which leads back to the stone age, while the equipment of viticulture and wine-making goes back, with the industry, to Gallic times, though, of course, not all the implements in use are of an equally remote origin. There is a pregnant reminder that the conversion of the sword into a ploughshare is more than a rhetorical trope in the observation that in primitive conditions the weapons of war do become the imple. ments of peaceful occupations when hostilities cease.

A legitimate pride of descent and a half-humorous, but wholly determined, practice of traditional ways of doing certain things is attributed to the Cape population of Dutch descent in a record of surviving customs by Eric Rosenthal ("Old Time Survivals in South Africa". Government Printer, Pretoria, 1936. Pp. 38). The survival of so much that, on a superficial view, is obsolete may seem remarkable in a community that is now essentially up to date, and of which some of the industries are highly mechanized. To some extent this may be due to a racial pride and race consciousness; but the real explanation lies deeper. It is part of an enduring environmental adaptation. The clue is afforded by the survival of the old ox-wagon, virtually unchanged since its first introduction from Holland by Jan van Riebeck in 1632, except for the addition of a brake in the eighteen-sixties, yet of which there are more than a hundred thousand in use in South Africa side by side with the automobile. This apparent anomaly may be explained by the fact that the ox wagon has been the efficient cause in the development of the characteristic South African civilization. When built in the traditional way and from the traditional materials, it is still the best, and indeed the only, means of transport which is fully adapted to the geographical conditions and the social and economic needs of the country. One useful feature of ox-wagon travel, the 'outspan' for night camping, still found in every community, serves both the old and the modern need in a country where distances are great and hotel facilities few.

\title{
Empire Surveys
}

$\mathrm{F}^{\mathrm{a}}$ RMERLY it was difficult for surveyors, more or less isolated in the Dominions and Colonies, to keep in touch with the advances in technique which are constantly occurring both as regards instruments and methods, cut off as they are from their fellow surveyors.

The institution of periodical conferences, held in the heart of the Empire, under the auspices of the Colonial and War Offices, has changed all this. Surveyors from different parts of the Empire meet and get in touch with each other as they never did before. Nothing but good can result from this. There has also been established a quarterly journal, the Empire Survey Review, devoted to survey technique and the discussion of matters of interest to the surveyor. At last year's conference, all the Dominions (except New Zealand), India and Colonies possessing survey departments, were represented, as well as many British scientific societies and universities.

At the conference, the report of which has lately been published*, some forty papers bearing on all branches of surveying and dealing with the latest instrumental developments were read and discussed. Of these, no less than eight dealt with matters con. nected with air survey, showing the importance now attached to this branch of the subject.

From such a mass of matter it is not easy to single out for notice particular subjects. Major M. Hotine has an interesting paper on signals for triangulation. Sufficient attention is not always paid to signals where accurate work has to be done. As the author points out in the case of opaque signals made of wood, it is very necessary in order to avoid warping

* Conference of Empire Survey Officers 1935. Report of Proceedings. (Colonial No. 111.) Pp. vi $+377+36$ plates. (London: H.M. Stationery Office, 1936.) 20s. net. and the movement of the signal due to the drying of material after erection, that they should be made of seasoned timber, instead of, as is usually done, from wood eut on the spot. Incidentally, Major Hotine points out that if primary triangulation is undertaken at all, it should be of first-class order and not "only good enough for immediate purposes". Someone is sure to want to extend it in the future, in which case it may have to be done all over again. Therefore every precaution should be taken with the observations, the best instruments should be used and suitable signals well centred over the marks, or the work will not conform with first-class triangulation. A new type of electric night projector is being brought out by Messrs. Cooke, Troughton and Simms, Ltd., which can be worked by a 12-volt accumulator such as is carried on a motor car. We understand it is being used by the Ordnance Survey in the retriangulation of Great Britain now in progress.

Many papers are read chiefly with the view of encouraging discussion. For example, a new instrument is experimented with; it is of considerable advantage to know what the experience of others has been with an instrument of the kind. When we consider how grudgingly money is allotted for survey purposes in Great Britain, it is astonishing to read that more than $£ 6$ per acre is spent on the survey of Georgetown and Malacca in the Federated Malay States. The value of survey out there is evidently known and appreciated.

Perhaps one of the most remarkable papers read before the conference was by Lieut. E. H. Thompson, R.E., on "An Automatic Plotting Machine for Air Photographs". This machine is from the designs of Mr. Fourcade, who has been working at this difficult problem for some years. Lieut. Thompson has 
constructed a most ingenious model from Meccano to illustrate the working of this complicated instrument. Without something of the sort, it is very difficult to understand how it functions.

Brigadier MacLeod pleads for the co-ordination of African surveys. He points out that some kind of arrangement should be come to among the various nations possessing African territory with the view of adopting uniformity of scales and projection of maps, before it is too late. So far, this has been achieved only in the case of the International "Carte du Mond" on the $1 / 1,000,000$ scale. He also urges the adoption of the metric unit. The progress of aviation has made this necessary since the airman passes so quickly from one territory to another. Unless something is done, Africa of the future will be saddled with a multiplicity of scales, styles and projections. As no other nation is likely to adopt the British units of measurement, unless we change to the metric system, yet another complication will be added to the map difficulties of the airman.

Before the conference terminated, resolutions were passed recommending that a central pool of survey instruments should be formed from which Dominions and Colonies could borrow on certain terms; that the Empire Survey Review should be continued notwithstanding some loss, as a means of keeping up the standards of surveying technique; a resolution emphasizing the necessity for basing all categories of survey on a proper geodetic foundation; a resolution recording the opinion of the conference as to the value of its proceedings for the discussion and interchange of views on the improvement of survey technique. The conference also decided that it is desirable to hold triennial conferences lasting for two weeks.

H. L. C.

\section{Electrical Interference with Broadcasting}

\begin{abstract}
THREE years ago the Institution of Electrical Engineers appointed a special committee to consider the trouble caused by the interference of various kinds of electrical devices with radio reception. This nuisance has been gradually getting worse owing to the growing sensitivity of modern receivers. The report has now been published (Inst. Elec. Eng., Savoy Place, W.C.2. 6d. post paid) and was commented upon in NATuRE of August 1. The committee was fully representative of all sections of the industry on both the radio and engineering sides.

A method of measurement of interference has been agreed upon, and instruments have been developed capable of indicating with sufficient accuracy the amount of interference caused by much of the electrical apparatus which causes trouble. The technical position has been cleared up, and it is considered that no undue extra expense will be involved in the design and construction of apparatus that will bring the interference caused within an acceptable standard. The apparatus which is likely to cause the most interference is classified as follows : (1) lifts in buildings ; (2) trolley-buses and trams; (3) household electrical appliances ; (4) small electric motors ; (5) 'neon' display signs ; (6) certain rectifiers for power plant and (7) electro-medical apparatus. In an appendix to the report, a brief account is given of the researches undertaken in connexion with these seven groups.
\end{abstract}

In addition, although there is at present little interference with ordinary broadcast reception due to the ignition systems on motor-vehicles, it is probable that, unless corrected, it will interfere with the television reception of the future. There are other causes of radio interference such as electric signalling gear on railways, but at present they produce only minor effects. Real progress has been made in finding the most effective methods of correction in each of the seven groups given above. As a result of Post Office activity, a considerable amount of radio interference correction has been taking place during the last few years.

The first case where radio interference correction was in effect made compulsory was that of traffic signals. The Ministry of Transport now requires all traffic signals to be fitted with components which effectively prevent interference. This was achieved without much difficulty. The second case was that of trolley-buses, where much practical progress has been made. It is now clear that the various technical aspects of the problem are approaching solution, and it is necessary to consider whether compulsory powers should be conferred on some authority so that radio interference may be suppressed in those cases where it can only be done with the help of such an authority. The manufacturers of appliances and plant definitely support the view that there should be some recognized 'mark' which could be affixed to all portable apparatus as a guarantee that the apparatus complies with noninterference requirements. They consider that the sale of appliances which do not meet those requirements should be prohibited. It is essential that imported articles should be subject to the same regulations as home-produced articles and should bear the 'mark'. It is only through legislation that this question can be dealt with successfully. As a rule, it is not the man who buys and uses the apparatus, but his neighbour, who suffers from the resulting interference.

In view of the fact that it is generally cheaper to incorporate suppression devices in the original design of the equipment than to fit them after installation, it is recommended that compulsory powers should be conferred on some authority. It is anticipated that there will be only a small number of owners of interfering equipment who will refuse to apply remedial measures. It is recommended that the Electricity Commissioners should be the authority to issue regulations regarding both new and existing equipments and that the Post Office be charged with enforcing them. British Standards Specifications have already been issued giving the standard ratings for condensers, 'resistors', inductors and similar apparatus for incorporation in suppression devices. The specification for a standard interference-measuring instrument will cover the characteristics and performance requirements recommended by the Special International Committee on Radio Interference. It will include a detailed design for a portable instrument which will enable manufacturers to 